\title{
Dimensional Variation of Aluminium Honeycomb Panel on Circular Cutting with Laser Jet Technology
}

\author{
Horațiu BULEA \\ Transilvania University of Brasov, Romania, bulea@unitbv.ro
}

\begin{abstract}
The cutting laser jet method can offer a suitable solution for manufacturing of aluminium honeycomb panel who are usually difficult to do. This paper presents the results of some experiments on laser jet cutting of circular holes into aluminium honeycomb panel, which can be further used for cutting holes in aluminium honeycomb panel. The main problem which occurs is the tapered shape of the hole, due to the mechanics of the process and the control of the kerf produced by the laser jet.The experiments considered several values of the main process parameters like power output, impulse frequency, fast feed rate on X and Y axes which have a direct influence on the part machinability. After measuring the parts, there were analysed the main dimensional parameters of precision to reveal the proper solution for obtaining the required quality of the process.
\end{abstract}

Keywords

aluminium honeycomb panel, circular on laser jet cutting, dimensional variation of cut diameters

\section{Introduction}

These aluminium honeycomb panel need to be drilled and a high quality are demanded than those elements are placed in key components of the aircrafts.

The defects that can be produced in the dry drilling of aluminium honeycomb panel are diameter deviation and damaged area of honeycomb. These defects are known as Break-IN (B-IN) and BreakOUT (B-OUT) [1]. First of them is based on the analysis of the diameter deviation. Second procedure is based on the damaged area. The parameters have been measured making use of image analysis techniques.

\section{Laser Cutting}

\subsection{The principle of laser cutting}

Laser cutting is a technology that uses a focused beam of high energy laser light to cut material by selectively burning, vaporizing and/or melting a highly localized area, while an assist gas is used to remove the material from the resulting cut. It is one of the fastest and most accurate methods for cutting a variety of metals and non-metals.

Nowadays, both gaseous (CO2) and solid-state (Nd:YAG) lasers are employed for cutting various materials. Since, in the case of $\mathrm{CO} 2$ lasers, the type of gas flow can affect the cutting performance, several laser subvariants can be identified, such as fast axial flow, slow axial flow, transverse flow, and slab lasers for. As an example, transverse flow lasers circulate the gas mix at a lower velocity, requiring a simpler blower, while slab or diffusion cooled resonators have a static gas field that requires no pressurization or glassware for protection [2].

The main advantages of laser cutting over other cutting methods can be summarised as follows:

- it can cut a variety of metals and non-metals;

- it can produce part accuracies better than $0.08 \mathrm{~mm}$;

- it can cut thinner metals at over $170 \mathrm{~mm} / \mathrm{s}$;

- it produces a narrower heat affected zone than plasma.

However, there are also several disadvantages to be considered [3]:

- high cost of the equipment;

- the thickness of materials that can be cut is very limited (10-20 mm at best); 
- the cutting of metals with highly reflective surfaces (such as aluminium, but also titanium, to some extent) can cause problems for the equipment (especially for the focusing lens);

- it can cause micro-fracturing in some materials;

- variations in the material's quality can affect the cutting results;

- the maintenance of the cutting equipment requires advanced knowledge;

- depending on the material being cut, noxious;

- fumes can be produced during the cutting process.

\subsection{Experimental components}

The experimental researches regarding the cutting precision were carried out on a NTX-48 Champion laser cutting machine manufactured by Mazak (Japan) using a CO2 laser with a laser wave length of $10.6 \mu \mathrm{m}$ and having following characteristic working parameters:

- maximal power output: $2 \mathrm{~kW}$;

- impulse frequency: from 0 to $2000 \mathrm{~Hz}$;

- maximal machining feed rate: $10 \mathrm{~m} / \mathrm{min}$;

- maximal fast feed rate on $\mathrm{X}$ and $\mathrm{Y}$ axes: $24 \mathrm{~m} / \mathrm{min}$;

- maximal fast feed rate on $\mathrm{Z}$ axis: $20 \mathrm{~m} / \mathrm{min}$;

- positioning precision on $\mathrm{X}$ and $\mathrm{Y}$ axes: $\pm 0.01 / 100 \mathrm{~mm}$;

- positioning precision on $\mathrm{Z}$ axis: $\pm 0.01 / 500 \mathrm{~mm}$.

\section{Run of the Experimental Tests}

The aim was to obtain, by laser cutting, holes in aluminium honeycomb panel Figure 1, depends on cutting parameters show in Table 1.

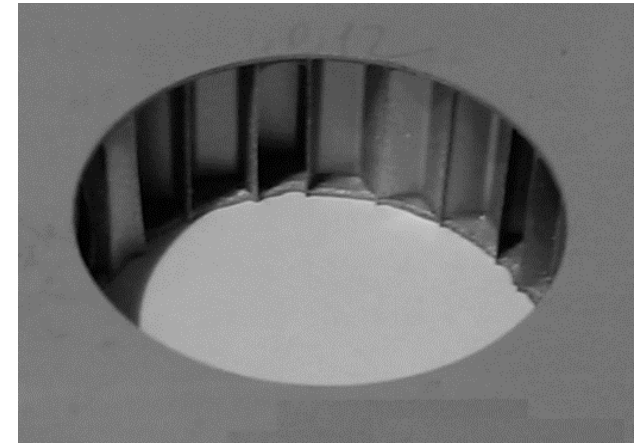

Fig. 1. Diameters results at entrance, and at exit of material

The workpieces were aluminium honeycomb panel. There were performed tests of machining circular holes with three values of the nominal diameter D, as D1 $=40 \mathrm{~mm}, \mathrm{D} 2=30 \mathrm{~mm}$, and D3 $=20$ $\mathrm{mm}$ in the workpieces of two different heights G, the first with $\mathrm{G} 1=12 \mathrm{~mm}, \mathrm{~m}=10 \mathrm{~mm}$, and $\mathrm{g}=1 \mathrm{~mm}$, and the second with G2 $=8 \mathrm{~mm}, \mathrm{~m}=6 \mathrm{~mm}$, and $\mathrm{g}=1 \mathrm{~mm}$, show in Figure 2, using different strategies and values for the cutting parameters presented in Table 1 .

Table 1. Parameters of cutting

\begin{tabular}{|l|c|c|}
\hline Parameter & Values & Measure units \\
\hline Feed rate speed V & $1 ; 2 ; 3$ & {$[\mathrm{~m} / \mathrm{min}]$} \\
\hline Power & $1400 ; 2000$ & {$[\mathrm{~W}]$} \\
\hline Impulse frequency & 1000 & {$[\mathrm{~Hz}]$} \\
\hline
\end{tabular}

In the present case, the aluminium honeycomb panel used was not found in the list of materials, so it was manually added ten machinability strategies tree speed rate $V=1 \mathrm{~m} / \mathrm{min}, \mathrm{V}=2 \mathrm{~m} / \mathrm{min}$, $\mathrm{V}=3 \mathrm{~m} / \mathrm{min}$, with two power $\mathrm{P} 1=1400 \mathrm{~W}$ and $\mathrm{P} 2=2000 \mathrm{~W}$. This values proved to be correct and the holes were cut in good conditions. 
RECENT, Vol. 19, no. 3(56), December, 2018

\section{Evaluation of the Dimensional Precision}

To evaluate the dimensional accuracy of the parts, there were performed measurements of the hole diameter, in two sections along the height, at the entrance, and the exit of the laser jet, Figure 2 [4].

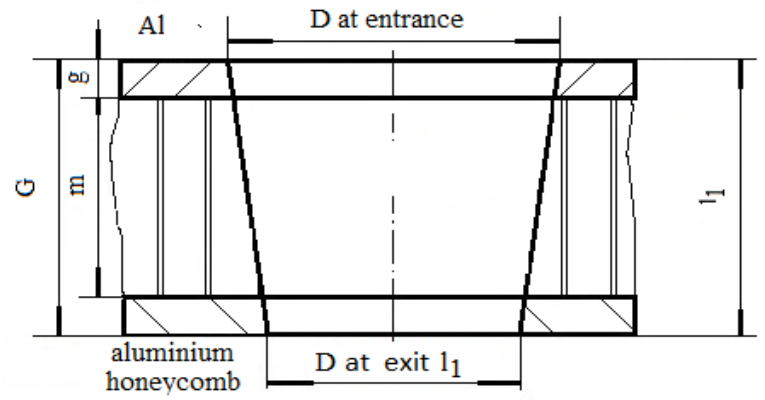

Fig. 2. Diameters results at entrance, and at exit of material

Table 2. Parameters of cutting for G1 $=12 \mathrm{~mm}$

\begin{tabular}{|c|c|c|c|c|}
\hline \multirow{2}{*}{$\begin{array}{c}\mathrm{V} \\
{[\mathrm{m} / \mathrm{min}]}\end{array}$} & \multicolumn{2}{|c|}{$\mathrm{P} 1=1400 \mathrm{~W}$} & \multicolumn{2}{c|}{$\mathrm{P} 2=2000 \mathrm{~W}$} \\
\cline { 2 - 5 } & $\begin{array}{c}\text { D at entrance } \\
{[\mathrm{mm}]}\end{array}$ & $\begin{array}{c}\text { D at exit } \\
{[\mathrm{mm}]}\end{array}$ & $\begin{array}{c}\text { D at entrance } \\
{[\mathrm{mm}]}\end{array}$ & $\begin{array}{c}\text { D at exit } \\
{[\mathrm{mm}]}\end{array}$ \\
\hline 1 & 40.032 & 40.010 & 40.028 & 40.010 \\
\hline 2 & 40.029 & 39.980 & 40.029 & 39.990 \\
\hline 3 & 40.031 & 39.950 & 40.030 & 39.980 \\
\hline 1 & 30.035 & 30.010 & 30.051 & 30.030 \\
\hline 2 & 30.032 & 29.980 & 30.052 & 30.010 \\
\hline 3 & 30.033 & 29.950 & 30.051 & 30.000 \\
\hline 1 & 20.050 & 20.024 & 20.055 & 20.032 \\
\hline 2 & 20.051 & 20.000 & 20.055 & 20.010 \\
\hline 3 & 20.050 & 19.960 & 20.052 & 19.970 \\
\hline
\end{tabular}

Table 3. Parameters of cutting for $\mathrm{G} 2=8 \mathrm{~mm}$

\begin{tabular}{|c|c|c|c|c|}
\hline \multirow{2}{*}{$\begin{array}{c}\mathrm{V} \\
{[\mathrm{m} / \mathrm{min}]}\end{array}$} & \multicolumn{2}{|c|}{$\mathrm{P} 1=1400 \mathrm{~W}$} & \multicolumn{2}{c|}{ P2 $=2000 \mathrm{~W}$} \\
\cline { 2 - 5 } & $\begin{array}{c}\text { D at entrance } \\
{[\mathrm{mm}]}\end{array}$ & $\begin{array}{c}\text { D at exit } \\
{[\mathrm{mm}]}\end{array}$ & $\begin{array}{c}\text { D at entrance } \\
{[\mathrm{mm}]}\end{array}$ & $\begin{array}{c}\text { D at exit } \\
{[\mathrm{mm}]}\end{array}$ \\
\hline 1 & 40.030 & 40.010 & 40.010 & 39.995 \\
\hline 2 & 40.030 & 39.990 & 40.020 & 39.990 \\
\hline 3 & 40.031 & 39.970 & 40.020 & 39.976 \\
\hline 1 & 30.026 & 30.004 & 30.050 & 30.031 \\
\hline 2 & 30.029 & 29.985 & 30.050 & 30.017 \\
\hline 3 & 30.028 & 29.960 & 30.051 & 30.005 \\
\hline 1 & 20.029 & 20.005 & 20.050 & 20.030 \\
\hline 2 & 20.025 & 19.977 & 20.051 & 20.015 \\
\hline 3 & 20.027 & 19.950 & 20.052 & 19.990 \\
\hline
\end{tabular}

Considering the mean values in Table 2 for G1 $=12 \mathrm{~mm}$ and in Table 3 for G2 $=8 \mathrm{~mm}$, the graphical variation of the hole diameter was pointed out in diagrams. Diagrams in Figure 3 present the dependence of the hole diameter D1 $=40 \mathrm{~mm}$ on the feed rates, at the entrance and at exit of pieces, diagrams in Figure 4 present the dependence of the hole diameter D2 $=30 \mathrm{~mm}$ on the feed rates, at the entrance and at exit of pieces of pieces with G1 $=12 \mathrm{~mm}$ for power P1 $=1400 \mathrm{~W}$. Diagrams in Figure 5 present the dependence of the hole diameter $\mathrm{D} 1=40 \mathrm{~mm}$ on the feed rates, at the entrance and at exit, diagrams in Figure 6 present the dependence of the hole diameter D3 $=20 \mathrm{~mm}$ on the feed rates, at the entrance and at exit of pieces with $\mathrm{G} 1=12 \mathrm{~mm}$ for power $\mathrm{P} 2=2000 \mathrm{~W}$. 
RECENT, Vol. 19, no. 3(56), December, 2018

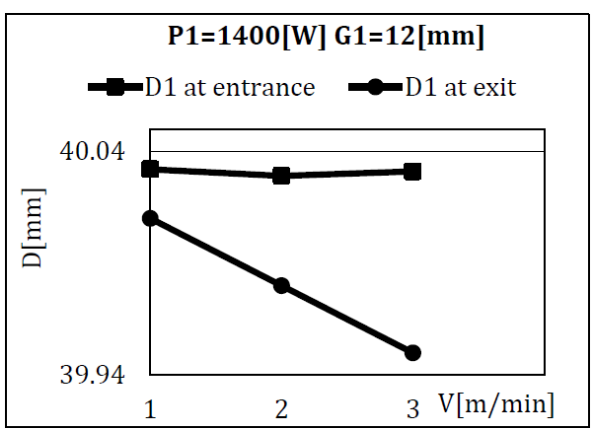

Fig. 3. The dependence of the hole diameter $\mathrm{D} 1=40 \mathrm{~mm}$ on the feed rates, at the entrance and at exit of pieces for G1 $=12 \mathrm{~mm}$

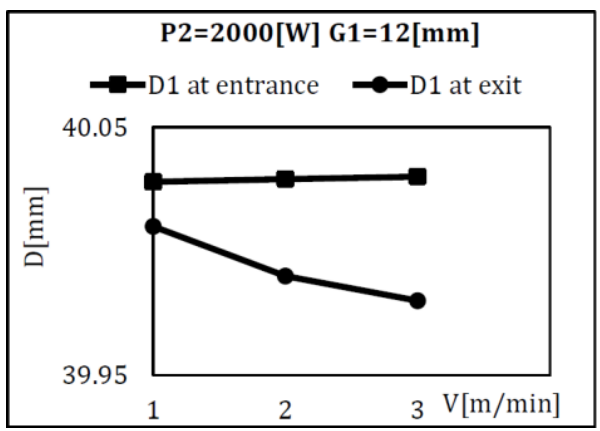

Fig. 5. The dependence of the hole diameter $\mathrm{D} 1=40 \mathrm{~mm}$ on the feed rates, at the entrance and at exit of pieces for $\mathrm{G} 1=12 \mathrm{~mm}$

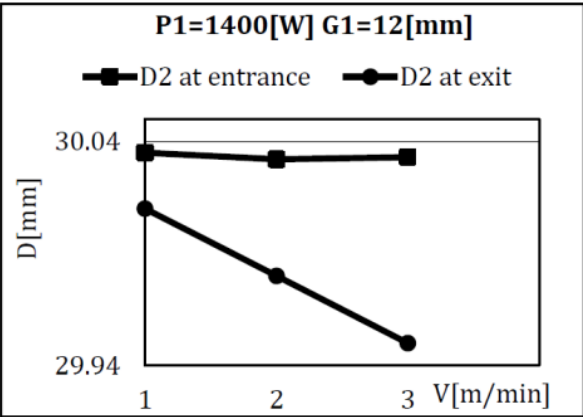

Fig. 4. The dependence of the hole diameter $\mathrm{D} 2=30 \mathrm{~mm}$ on the feed rates, at the entrance and at exit of pieces G1 $=12 \mathrm{~mm}$

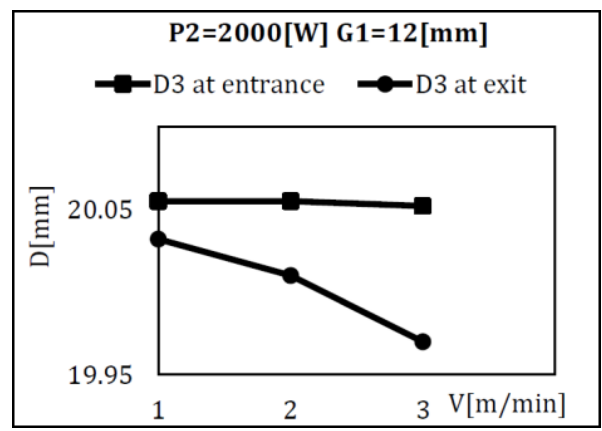

Fig. 6. The dependence of the hole diameter D3 $=20 \mathrm{~mm}$ on the feed rates, at the entrance and at exit of pieces $\mathrm{G} 1=12 \mathrm{~mm}$

Diagrams in Figure 7 present the dependence of the hole diameter D1 $=40 \mathrm{~mm}$ on the feed rates, at the entrance and at exit of pieces, diagrams in Figure 8 present the dependence of the hole diameter $\mathrm{D} 2=30 \mathrm{~mm}$ on the feed rates, at the entrance and at exit of pieces of pieces with G1 $=12 \mathrm{~mm}$ for power $\mathrm{P} 1=1400 \mathrm{~W}$. Diagrams in Figure 9 present the dependence of the hole diameter D1 $=40 \mathrm{~mm}$ on the feed rates, at the entrance and at exit, diagrams in Figure 10 present the dependence of the hole diameter $\mathrm{D} 3=20 \mathrm{~mm}$ on the feed rates, at the entrance and at exit of pieces of pieces with $\mathrm{G} 2=8 \mathrm{~mm}$ for power $\mathrm{P} 2=2000 \mathrm{~W}$.

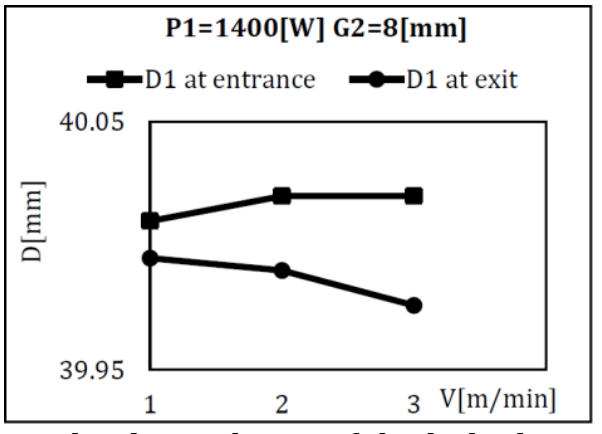

Fig. 7. The dependence of the hole diameter

$\mathrm{D} 1=40 \mathrm{~mm}$ on the feed rates, at the entrance and at exit of pieces for $\mathrm{G} 2=8 \mathrm{~mm}$

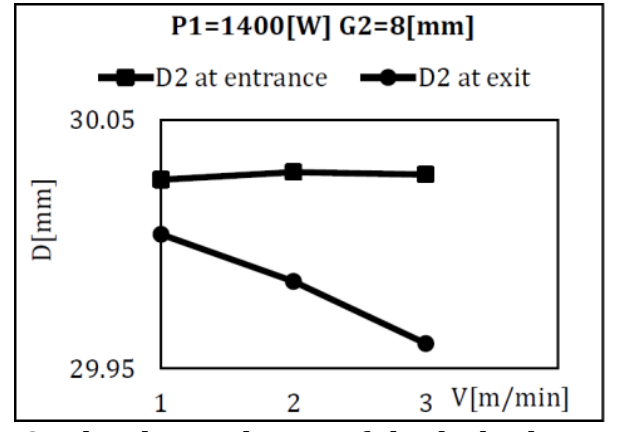

Fig. 8. The dependence of the hole diameter $\mathrm{D} 2=30 \mathrm{~mm}$ on the feed rates, at the entrance and at exit of pieces $\mathrm{G} 2=8 \mathrm{~mm}$

The diagrams shown in Figures $3 \ldots 10$ point out the following statements on the parts' accuracy in terms of dimensional deviation from the main influence on the dimensional precision of the circular cutting has the feed rate, as seen in all diagrams:

-all the linear cutting has a tapered surface, wider at entrance and narrower at exit, Figures 3...10,

looking at the direction of the abrasive water jet; 
RECENT, Vol. 19, no. 3(56), December, 2018

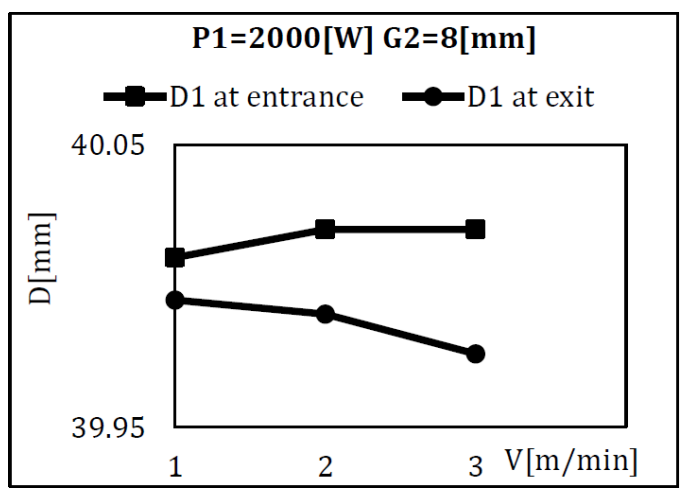

Fig. 9. The dependence of the hole diameter $\mathrm{D} 1=40 \mathrm{~mm}$ on the feed rates, at the entrance and at exit of pieces for $\mathrm{G} 2=8 \mathrm{~mm}$

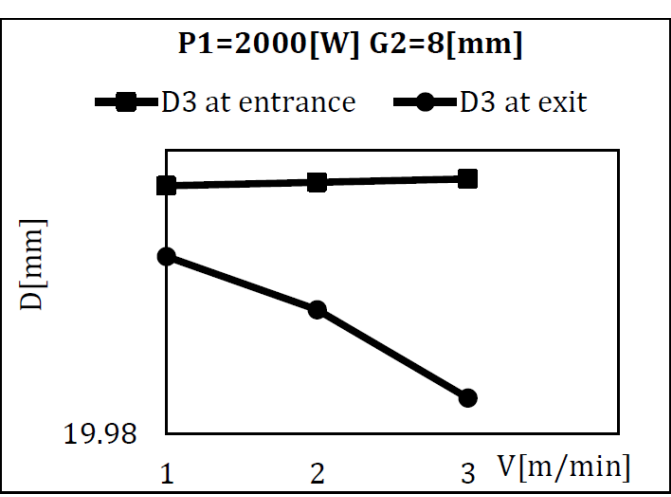

Fig. 10. The dependence of the hole diameter $\mathrm{D} 3=30 \mathrm{~mm}$ on the feed rates, at the entrance and at exit of pieces $\mathrm{G} 2=8 \mathrm{~mm}$

-this is a general effect of a much longer contact with the jet at the entrance surface compared to the exit one;

-the precision of circular cutting increase with decreases of the feed rate, as seen in diagrams this can be explained by a longer time contact with the laser jet when the feed rate is smaller;

-the precision of the linear cutting increase with decreases of nozzle diameter as seen in Figures 3...10; -at the exit surface, the deviation dispersal is smaller than at the entrance for all cutting and height of pieces, Figures $3 \ldots 10$, probably because of the uncontrollable dispersal phenomenon of the laser jet in contact with the particles already cut from the workpiece;

-at power $\mathrm{P} 1=1400 \mathrm{~W}$ the deviation field spreads between $0.022 \mathrm{~mm}$ and $0.026 \mathrm{~mm}$ at G1 $=12 \mathrm{~mm}$ for $\mathrm{D} 1=40 \mathrm{~mm}$, between $0.049 \mathrm{~mm}$ and $0.051 \mathrm{~mm}$ for $\mathrm{D} 2=30 \mathrm{~mm}$, and between $0.081 \mathrm{~mm}$ and 0.090 $\mathrm{mm}$ for $\mathrm{D} 3=20 \mathrm{~mm}$;

-at power $\mathrm{P} 2=2000 \mathrm{~W}$ the deviation field spreads between $0.018 \mathrm{~mm}$ and $0.023 \mathrm{~mm}$ at $\mathrm{G} 1=12 \mathrm{~mm}$ for $\mathrm{D} 1=40 \mathrm{~mm}$, between $0.039 \mathrm{~mm}$ and $0.045 \mathrm{~mm}$ for D2 $=30 \mathrm{~mm}$, and between $0.051 \mathrm{~mm}$ and $0.072 \mathrm{~mm}$ for $\mathrm{D} 3=20 \mathrm{~mm}$;

-at power P1 $=1400 \mathrm{~W}$ the deviation field spreads between $0.020 \mathrm{~mm}$ and $0.024 \mathrm{~mm}$ at $\mathrm{G} 2=8 \mathrm{~mm}$ for $\mathrm{D} 1=40 \mathrm{~mm}$, between $0.040 \mathrm{~mm}$ and $0.048 \mathrm{~mm}$ for D2 $=30 \mathrm{~mm}$, and between $0.061 \mathrm{~mm}$ and $0.077 \mathrm{~mm}$ for $\mathrm{D} 3=20 \mathrm{~mm}$;

-at power P2 $=2000 \mathrm{~W}$ the deviation field spreads between $0.015 \mathrm{~mm}$ and $0.020 \mathrm{~mm}$ at $\mathrm{G} 2=8 \mathrm{~mm}$ for $\mathrm{D} 1=40 \mathrm{~mm}$, between $0.030 \mathrm{~mm}$ and $0.036 \mathrm{~mm}$ for D2 $=30 \mathrm{~mm}$, and between $0.044 \mathrm{~mm}$ and $0.062 \mathrm{~mm}$ for $\mathrm{D} 3=20 \mathrm{~mm}$;

-dimensional accuracy decreases with increasing of the feed rate as shown in all diagrams;

-the significant difference between diameters at entrance and at exit are $0.090 \mathrm{~mm}$, at feed rate $\mathrm{V}=3$ $\mathrm{m} / \mathrm{min}$, for $\mathrm{G} 1=12 \mathrm{~mm}, \mathrm{P} 1=1400 \mathrm{~W}$ and $\mathrm{D} 3=20 \mathrm{~mm}$;

-the minimal difference between diameter at entrance and at exit $0.015 \mathrm{~mm}$, is at feed rate $\mathrm{V}=1 \mathrm{~m} / \mathrm{min}$, for $\mathrm{G} 2=8 \mathrm{~mm}$ at $\mathrm{P} 2=2000 \mathrm{~W}$ and $\mathrm{D} 1=40 \mathrm{~mm}$;

-the thickness of the part have an important influence on the dimensional precision, but it has an indirect influence as it determines the values of the feed rate, chosen to assure a complete penetration of the hole.

\section{Conclusions}

Machining of aluminium honeycomb panel is a difficult task, because of the material hardness and stiffness. When circular holes are needed into such materials, the laser jet is a very suitable method, with a reasonable cost and the required quality of the parts. The experimental tests presented in this paper proved that laser jet can be used with good results for circular cutting in honeycomb panel. The main challenge is to find the proper values of the working parameters to obtain the required surface accuracy.

The conclusions are:

-the main influence on the dimensional precision of the circular holes has the feed rate, as seen in all diagrams; 
-all the circular hole has a tapered surface, wider at entrance and narrower at exit, Figures 3 to 10, looking at the direction of the Laser jet, this is a general effect of a much longer contact with the abrasive stream at the entrance surface compared to the exit one;

-the precision of the cut of exit diameters increase with decreases of the feed rate, as seen in diagrams. This can be explained by a longer time contact with the abrasive jet when the feed rate is smaller;

-the precision of the cut of exit diameters decreases with decreases of the holes diameters, as seen in diagrams;

-the precision of the cut of exit diameters increase with increase of the power of laser jet, as seen in diagrams.

Further research is encouraged to establish the cutting conditions in other cases of part's shape and other materials.

\section{References}

1. Mayuet P., Arroyo P., et al. (2014): Comparison of Diameter and Area Change Based Methods for Evaluating BreakIN and Break-OUT Damages in Dry Drilled Holes of Aeronautical Carbon Fiber Composites. Materials Science Forum, ISSN 1662-9752, Vol. 797, p. 35-40, https://doi.org/10.4028/www.scientific.net/MSF.797.35

2. Salguero J., Calamaz M., et al. (2014): Cutting Forces Prediction in the Dry Slotting of Aluminium. Materials Science Forum, ISSN 1662-9752, Vol. 797, p. 47-52, https://doi.org/10.4028/www.scientific.net/MSF.797.47

3. Abdel-Rahman A.A. (2010): An Abrasive Laser jet Model for Cutting Ceramics. (Proc. of Int. Conf. on) Mathematical Models for Engineering Science, WSEAS Press, ISBN 978-960-474-252-3, Puerto de la Cruz, Tenerife, Spain, http://www.wseas.us/e-library/conferences/2010/Tenerife/MMES/MMES-08.pdf

4. Filip A.C., Bulea H. (2013): Roughness variation and deviation from the perpendicularity of high concentrated ceramic alumium oxide on linear cutting in abrasive jet machining technology. Advances in Production, Automation and Transportation Systems, ISSN 2227-4588, Proceedings of the 6th International Conference on Manufacturing Engineering, Quality and Production Systems (MEQAPS '13), WSEAS Press, ISBN: 978-161804-193-7, p. 201-205, http://www.wseas.us/e-library/conferences/2013/Brasov/ICAPS/ICAPS-36.pdf 